\title{
The conduction velocities of peripheral nerve fibres conveying sensations of warming and cooling
}

\author{
CLARE J FOWLER, K SITZOGLOU, Z ALI, PÄIVI HALONEN \\ From the Reta Lila Weston Institute of Neurological Studies, The Middlesex Hospital Medical School, \\ London, $U K$
}

SUMMARY With the current practice of measuring thresholds for warming and cooling separately, the question of the exact nature of afferents subserving these sensations assumes new importance.

Experiments to measure reaction times to warming and cooling stimuli at two sites on the lower limb are described. The conduction velocity for each sensation was estimated from the conduction distance and conduction time in the limb. The estimated mean conduction velocity for warming was 0.5 , SD $0.2 \mathrm{~m} / \mathrm{s}$ and cooling $2 \cdot 1$, SD $0.8 \mathrm{~m} / \mathrm{s}$. These figures confirm that the sensation of warming is conveyed in unmyelinated and cooling in small myelinated peripheral nerve fibres.

There are now several methods for quantitating cutaneous thresholds for thermal sensations that have as their central working part Peltier thermoelectric modules. ${ }^{1-6}$ These modules are made up of series of bimetallic junctions mounted between two flat ceramic leaves and either surface may be made to heat or cool according to the Peltier principle. This principle states that when current is passed across a junction of two dissimilar metals which have special thermoelectric properties, cooling occurs on one side and warming on the other, depending on the polarity of the current. This property has meant that several of the thermal testing systems are able to test the threshold for warming and cooling separately $y^{3-6}$ and thus provide figures for the threshold of both modalities.

The capability of measuring the threshold for warming and cooling separately is very valuable, since it is held that the two modalities are conveyed by different peripheral nerve fibres: sensations of warming in unmyelinated peripheral nerve fibres and those of cooling in small myelinated fibres. Estimation of thresholds can therefore be used to examine the functional integrity of these fibres which are inaccessible to clinical electrophysiological investigations. Nerve conduction studies using surface recording electrodes examine only conduction in the largest myelinated fibres and even needle near nerve recording tech-

Address for reprint requests: Dr Clare J Fowler, Department of Clinical Neurophysiology, The Middlesex Hospital, London WIN 8AA, UK.

Received 8 December 1987 and in revised form 13 April 1988. Accepted 15 April 1988 niques cannot measure conduction velocities of less than $10 \mathrm{~m} / \mathrm{s}^{7}$ Examination of the composition of human nerve has shown that the largest myelinated fibres constitute a minority, between one third and one quarter of the total nerve fibres of peripheral nerve, ${ }^{89}$ and it could be argued that although methods of examination of nerve conduction using electrical stimuli are objective, they are a poor measure of total nerve function.

The small myelinated and unmyelinated fibres may be selectively diseased in neuropathies associated with disturbances of pain; either those characterised by spontaneous pain or neuropathies with a loss of perception of pain. Neuropathies involving the peripheral autonomic nervous system also affect these groups of fibres. It is therefore timely to review what is known about the nature of thermal afferents in human peripheral nerve and confirm the statement that sensory modalities of warming and cooling are conveyed separately, in unmyelinated and small myelinated fibres respectively.

Information concerning the conduction velocity of afferent peripheral nerve fibres conveying thermal sensations in humans comẹs from four different sources. The most direct evidence would be from microneurographic studies of units responding to warming and cooling in awake human subjects, but such information is very limited.

\section{Sensory unit studies}

Unitary recordings from many different animal studies have shown that in subprimates both warming and cooling, with a few exceptions, are conveyed in fibres 
of unmyelinated conduction velocity. ${ }^{10-13}$

The results from primate studies reveal a different picture; the majority of fibres conveying cooling having conduction velocities in the range of thinly myelinated A delta fibres ${ }^{114-16}$ although a small number of unmyelinated cooling afferents have also been reported. ${ }^{11} 14$ Warming in primate limb nerves is conveyed in fibres with non-myelinated conduction velocities. ${ }^{1718}$ Warming afferents on the face of monkeys appear to be different, two-fifths of units examined had A delta conduction velocities. ${ }^{19}$

Quite marked inter species differences in the type of fibres conveying thermal sensations exist, and direct evidence from humans would be valuable. Surprisingly there have been relatively few reports of microneurographic studies of human thermal afferents when compared with the number of detailed studies of human mechanoreceptors afferents. ${ }^{20}$ This paucity is unexplained since various groups of workers have perfected the techniques for recording from the appropriate groups of nerve fibres. ${ }^{2122} \mathrm{~A}$ possible explanation is that numerically the thermal afferents form a small proportion of the total nerve fibres in both the small myelinated and unmyelinated categories. Also in microneurographic experiments the nerve has not, of course, been cut proximally and sympathetic efferent activity may obscure any background firing in thermal afferents.

Of $125 \mathrm{C}$-fibre units recorded from human radial, peroneal or sapheneous nerves, only five were identified as specific warm receptor afferents. ${ }^{23}$ Another 12 warm receptor units have been reported ${ }^{24}$ but conduction velocity was measured in only two: both had unmyelinated fibre conduction velocities. ${ }^{25}$

There has been a solitary report of cooling receptors afferents ${ }^{26}$ and although the dynamic responses to cooling of four receptors were studied, no measurement of conduction velocity was made, Adriaensen $e t a^{22}$ reported their findings of recording from $140 \mathrm{~A}$ delta fibres in the radial nerve of man but did not encounter any specific cooling receptors.

\section{Dissociated loss of thermal sensibility by nerve blocking procedures}

Conduction of impulses in peripheral nerve may be blocked by injection of local anaesthetic or mechanical pressure on the nerve. Each procedure is to some extent selective for the diameter of fibre it first affects. Blocking experiments have been used to examine the differential conduction of the sensory afferents for thermal sensations, by creating a selective block of either large or small nerve fibres, and observing to what extent cooling or warming sensibility are affected. The finding that one modality can be impaired while the other remains relatively intact supports the view that the two sensations are conveyed by separate groups of nerve fibres.

(i) Local anaesthetic nerve blocks The statement that local anaesthetics preferentially block activity in small nerve fibres originates from the work of Gasser and Erlanger. ${ }^{27}$ These pioneers were experimenting with methods of altering the compound nerve action potential in ways which would add to their understanding of the relationship between fibre size and conduction velocity. Demonstrating that in those nerve preparations where they were able to demonstrate a differential action of procaine, the potential shortened mostly from behind, they concluded that "in general small fibres are blocked before large ones." However, they also stressed that "the amount of differential action was variable." This latter observation has received less attention.

Various experiments since have examined the effect of local anaesthetic on peripheral nerve and have all, with one exception, ${ }^{28}$ found that within the myelinated group of fibres, block occurs first in the smallest. $^{29-31}$ However, this differential effect is by no means absolute and the apparent selective blocking of small fibres may merely be due to a faster rate of onset of block in this subgroup. More relevant to the current argument, the extent to which the small myelinated fibres are affected before the unmyelinated fibres, remains very uncertain. For this reason conclusions concerning the nature of afferents conveying warming and cooling based on observations of first sensation lost should be viewed with circumspection. (ii) Sensory experiences following local anaesthetic nerve blocks Many observations on the changes in sensation that occur following perineural injection of local anaesthetic agents, have been made. Although there is almost universal agreement that pain is lost whilst touch is intact, there is no consensus as to the order in which warming and cooling are lost. In 1929 Gasser and Erlanger ${ }^{27}$ reviewed the literature from 1886 to the time of their writing, and found three papers claiming cold is blocked before warmth and one that showed temperature sensations were lost before pain. Nathan ${ }^{32}$ reported the results of intrathecal analgesia on cutaneous sensibility and found that pain and warmth sensibility were usually lost at the same time and this before cold sensibility, although there were exceptions to this order. Fruhstorfer et al, ${ }^{33}$ carried out local anaesthetic nerve blocks with the expressed intention of examining the sensory afferents conveying the two types of thermal sensation. Ulnar nerve blocks were carried out with a local anaesthetic agent in 39 control subjects. In 22 subjects warm sensibility was blocked before cooling sensibility, in 10 the block was simultaneous but in seven cold sensibility was blocked before warm.

The lack of a constant finding in such experiments may be accounted for by the many factors which 
affect the action of a local anaesthetic agent on a group of nerve fibres. These include several variables, such as the proximity of the anaesthetic injection, local blood flow conditions and the lipid solubility of the agent. ${ }^{31}$ All these factors will have influenced the precise state of chemical equilibrium of the agent in each experiment and so determined whether the small myelinated or unmyelinated fibres were most affected. (iii) Compression blocks In contrast to blocks produced by local anaesthetic, compression of peripheral nerve results in a clearly differentiated block, the large myelinated fibres being affected first.

Gasser and Erlanger ${ }^{27}$ describe how the alpha potential "seemed to melt away from the fluorescent figure of the action potential on the screen of the tube" with mechanical pressure. This was applied by a cuff directly on to the nerve between the stimulating and recording sites. At a late stage of the block the delta wave was "essentially intact" at a time when the alpha peak was completely lost. Torebjork and Hallin $^{33}$ using microneurographic recording techniques, found a highly selective effect on large myelinated fibres of direct pressure on the nerve. Mackenzie et $a l^{35}$ using a similar experimental arrangement, observed the effect of pressure on the recorded neurogram, and found an early and total loss of the $A$ beta-gamma fibres at a time when $C$ fibres were not affected. It was shown, with a single exception that, when cold perception was absent, $A$ delta fibre potentials could no longer be seen in the averaged neurogram. At this stage warmth discrimination was somewhat impaired but still functional and a $\mathbf{C}$ fibre response could still be averaged.

\section{Cortically recorded evoked responses to thermal stimuli}

Several of the groups of workers who have been interested in human thermal physiology have recorded cortically evoked responses to warming and cooling stimuli. Their results are summarised in the table.

Thermal potentials have proved difficult to evoke, requiring very rapidly changing thermal stimuli, greatly in excess of threshold intensities. Because of the rapid heat transfer required, the equipment has been cumbersome and only a few stimuli given.

Table Cortical evoked responses to thermal stimuli

\begin{tabular}{llll}
\hline & Site & Peak latency & Author \\
\hline Cooling & Lip & mean $228 \mathrm{~ms}$ & Fruhstorfer et $a l^{37}$ \\
& Hand & mean $396 \mathrm{~ms}$ & Fruhstorfer et $a l^{37}$ \\
& Hand & $300-360 \mathrm{~ms}$ & Duclaux et al ${ }^{38}$ \\
& Hand & $178-200 \mathrm{~ms}$ & Jamal et $a l^{40}$ \\
Warming & Lip & mean $343 \mathrm{~ms}$ & Fruhstorfer et $a l^{37}$ \\
& Hand & mean $602 \mathrm{~ms}$ & Fruhstorfer et $a l^{37}$ \\
& Hand & $280-356 \mathrm{~ms}$ & Chatt and Kenshalo \\
& Hand & $280-350 \mathrm{~ms}$ & Jamal et $a l^{40}$ \\
\hline
\end{tabular}

Fruhstorfer et al,,$^{36}$ recorded cortically evoked potentials in response to warming and cooling stimuli applied to the lip or thenar eminence. At each site, the latency of responses was significantly shorter with cold stimulation than with warming (table). Duclaux et al, ${ }^{38}$ recorded the evoked response to cooling stimuli applied to the hand. A response was only obtained in 10 of 12 subjects with an onset between 70 and 300 $\mathrm{ms}$. The peak latency was less variable occurring between 300 and $360 \mathrm{~ms}$ (table). No response to warming could be obtained. Chatt and Kenshalo ${ }^{39}$ used warming stimuli at the same site as that used by $\mathrm{Du}$ claux $e t$ al,${ }^{38}$ but at greater intensity and higher starting temperature and recorded a response in three subjects. Jamal et al, ${ }^{40}$ used a rapid $21 \mathrm{~Hz} 8^{\circ} \mathrm{C}$ temperature change stimulus, for both warming and cooling, and applied this to the back of the hand and recorded from the contralateral cortex. The latency values obtained are most similar to those obtained by Chatt and Kenshalo. The authors emphasis that the response is highly dependent on the rate of temperature change and this fact may account of some of the variability in the latency of the responses.

The most interesting fact to emerge from this series of results is the consistent finding of a longer latency peak for warming than for cooling. This supports the view that the two modalities are conveyed by separate fibres with different conduction velocities. But since the absolute latency also includes the time taken foro the utilisation of the stimulus, spiral conduction and conduction across an unknown number of synapses in the central nervous system, no further conclusion may be drawn.

\section{Reaction time to thermal stimuli}

Reaction times to thermal stimuli have been studied by several different groups of workers. ${ }^{4-44}$ Some of these earlier reports suffer from the problem that the skin was touched by warm or cold probes and the subject asked to respond as soon as they felt a distinct

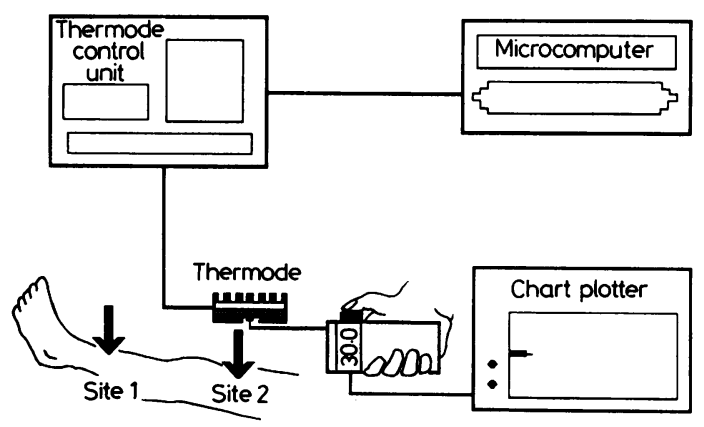

Fig 1 Experimental design used for measuring reaction times to thermal stimuli from two separate sites on the leg. 


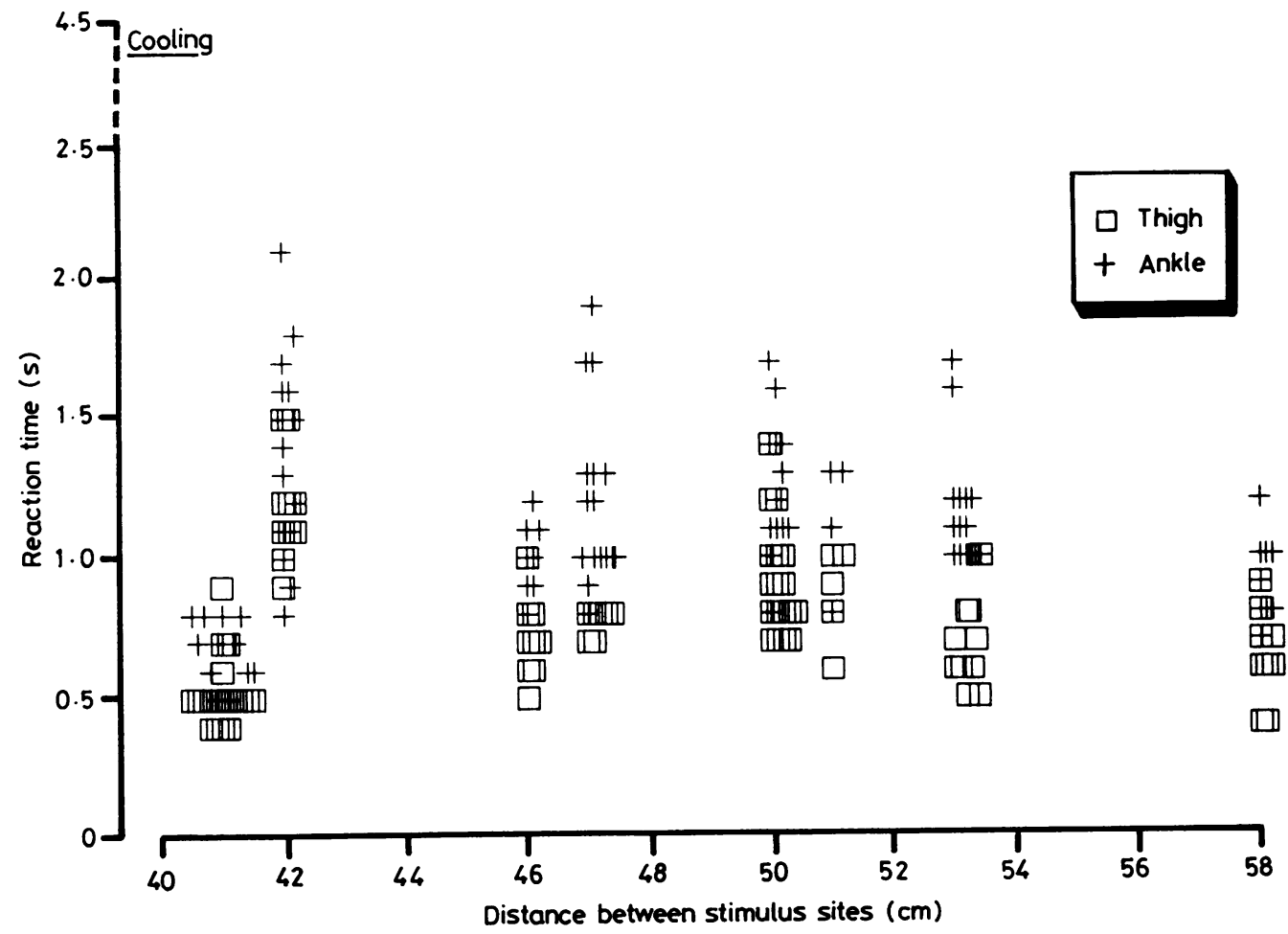

Fig 2 Reaction times to cooling stimuli applied at the ankle and the thigh.

thermal sensation after the initial contact.

Experiments with radiant warming ${ }^{42}$ avoided the problem of initial mechanical contact but no attempt was made to estimate conduction velocity, nor was it possible to examine the conduction velocity for cooling. Fruhstorfer et $a l,{ }^{44}$ are the only group to have studied reaction times using a Peltier stimulator. In a series of experiments warm and cold stimuli were applied to the right upper lip, thenar eminence and medial side of right foot just below the ankle. The reaction times for cold stimuli were shown to be significantly shorter than those for warm stimuli and the warm-cold latency difference increased in proportion to the increase in afferent pathway distance. A conduction velocity was estimated by calculating liphand latency differences and dividing this into the figure measured for the difference between the liphand afferent pathway. Conduction velocities for cooling and warming of $4.5 \mathrm{~m} / \mathrm{s}$ and $2.1 \mathrm{~m} / \mathrm{s}$ respectively were obtained. Measurement of the afferent pathway in such an experimental arrangement poses some difficulty and the assumption that the central processing of stimuli from the face is the same as that of the hand must be open to some doubt. To lessen these problems we carried out a series of reaction time experiments in which thermal stimuli were applied at a proximal and distal sites on the same limb.

\section{Subjects and method}

Nine volunteers, three male and six female, between the ages of 23-52 years were studied. The subject sat at rest in a comfortable chair with the thermode attached in firm contact to the test site, first at the ankle and then at the thigh. The equipment used was a modified arrangement (fig 1) of the thermal threshold measuring device described by Fowler et al. ${ }^{6}$ The thermode containing a thermoelectric Peltier module, was connected to the Thermode Control Unit, which contains a programmable power supply under the control of a small microcomputer Epson HX20. A program in BASIC produced randomly alternating warming or cooling pulses at irregular intervals. The output of the thermocouple in the thermode (usually connected to the microcomputer when the system is used to measure thresholds), was for these experiments connected to a paper chart recorder via the analogue output of a digital display thermometer. Without warning an abrupt cooling or warming stimulus was given and the subject was required to operate a thumb switch as soon as it had been perceived. The switch the subject operated was on the digital display thermometer, so that the temperature change of the thermode and the instant of the subject's response was recorded on paper $(60$ $\mathrm{cm} /$ minute) for later analysis. The rate of temperature change was set to the maximum power output of the ther- 


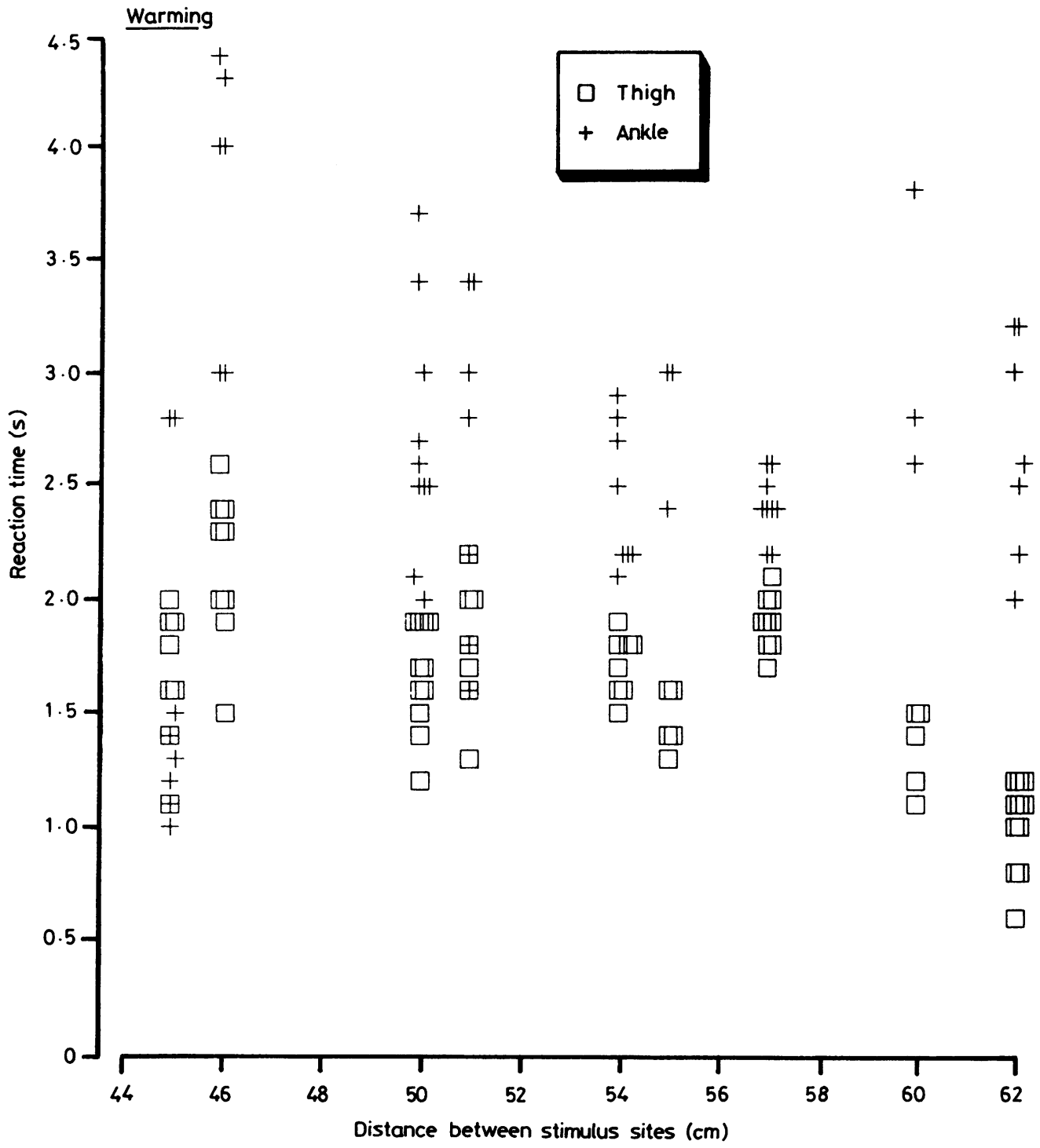

Fig 3 Reaction times to warming stimuli applied at the ankle and the thigh.

mode control unit, giving a fixed rate of $5^{\circ} \mathrm{C} / \mathrm{s}$ warming and $2 \cdot 5^{\circ} \mathrm{C} / \mathrm{s}$ cooling.

Up to 10 measurements of reaction time to both warming and cooling were made from each site. The distance between the two stimulating sites was measured and the difference between the mean reaction time for each site, calculated. From these figures, the conduction time for the sensation to traverse the length of the limb was obtained and, an estimate of conduction velocity for each sensation was calculated.

\section{Results}

The reaction times for each test stimulus given at the ankle and the thigh, are shown in (fig 2) cooling and (fig 3) warming. The $x$ axis of each figure is the distance between stimuli sites which is related to leg length.

The main points are clear from these figures; the reaction time for cooling from the two sites are much closer together than are the values obtained for warming, and the absolute reaction times for stimulation at the proximal site are shorter for cooling than for warming.

Using the mean reaction time for each subject at each site, a conduction time was obtained and the 


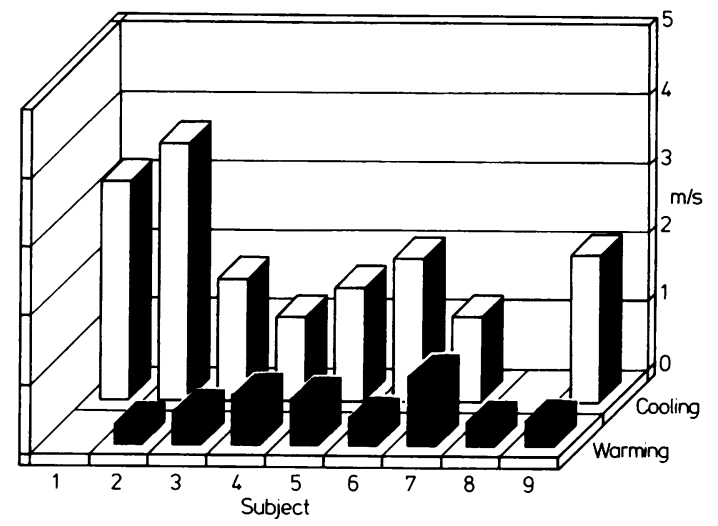

Fig 4 Estimated conduction velocity of peripheral fibres conveying sensations of cooling and warming.

conduction velocity estimated by dividing the conduction distance between stimulation sites by the conduction time. Figure 4 shows the values obtained in nine subjects for estimated conduction velocity for each thermal modality. In all cases the conduction of warming was slower than that of cooling. The mean values for eight subjects are $0.5, \mathrm{SD} 0.2 \mathrm{~m} / \mathrm{s}$ for warming and $2 \cdot 1, \mathrm{SD}-0 \cdot 8 \mathrm{~m} / \mathrm{s}$ for cooling.

\section{Discussion}

Considered overall, evidence from the literature does support the hypothesis that the two types of thermal sensation are conveyed by separate fibres, although there is no single definitive study. The microneurography studies in humans are surprisingly incomplete and no data exists from human lower limb studies. It appears that there are major species differences in peripheral nerve sensory function but the evidence from animal primate studies is strong that at least in limb nerve, warming travels at unmyelinated and cooling small myelinated fibre conduction velocity.

Experiments using nerve blocking techniques have produced conflicting results, but this is almost certainly because of the imperfectly selective action of local anaesthetic. Pressure nerve block experiments which have a more selective action have been much less studied.

The results from cortically recorded evoked potentials give widely differing latencies but there is the consistent finding that the latency for warming is longer than for cooling. The latency of a cortical potential is comprised of several discreetly timed events in addition to conduction in the peripheral nerve. The utilisation time taken for the stimulus to activate the receptors is unknown, but if, as has been suggested, the warm receptors are much deeper in the dermis than the cold receptors ${ }^{4145}$ the time taken for thermal diffusion through the tissues alone could account for the relative delay of the potentials in response to warming. In addition the central nervous system pathway and number of synapses for thermal afferents is unknown and may differ between warming and cooling. Thus although the results from this type of experiment are consistent with the hypothesis of slower conduction for warming than cooling, they are by no means proof of that fact.

Subtraction of reaction times to stimuli at separated sites offers a simple and non-invasive method for estimating conduction velocity. The use of this arithmetical procedure eliminates all unmeasurable variables so that only the time taken for the sensation to traverse the measured distance is considered. The validity of this method rests on two assumptions, first, that the central nervous system processing time for each stimulus site is the same and secondly that the speed of response by the receptors at the two sites is the same. The possibility that the central processing time of two stimuli applied on the same limb is more similar than it would be were the stimuli to be applied to different limbs, seems likely, but cannot be proved. The density of receptors at the ankle and the thigh is almost certainly different, but this probably affects the threshold value rather than speed of reaction.

The figures obtained in this experimental arrangement are entirely consistent with unmyelinated fibre conduction velocity for warming and small myelinated fibre conduction of cooling. Thermal thresholds should therefore be regarded as valuable measures of function of these peripheral nerve populations.

PH and ZA were supported by the generosity of Imperial Chemical Industries. We thank Dr Jose Ochoa, Dr G Jamal and Dr Bruce Lynn for helpful discussions.

\section{References}

1 Dyck PJ, Zimmerman IR, O'Brien PC, et al. Introduction of automated systems to evaluate touch-pressure, vibration and thermal cutaneous sensations in man. Ann Neurol 1978; 4:502-10.

2 Fruhstorfer H, Linblom U, Schmidt WG. Method for quantitative estimation of thermal thresholds in patients. $J$ Neurol Neurosurg Psychiatry 1976;39:1071-5.

3 Arezzo JC, Schaumburg HH, Laudadio C. Thermal sensitivity tester. Diabetes 1986;355:590-2.

4 Bertelsmann FW, Heimans JJ, Weber EJM, et al. Thermal discrimination thresholds in normal subjects and patients with diabetic neuropathy. J Neurol Neurosurg Psychiatry 1985; 48:686-90.

5 Jamal GA, Hansen S, Weir AJ, et al. An improved automated method for the measurement of thermal thresholds. 1. Normal subjects. J Neurol Neurosurg Psychiatry 1985;48: 354-60. 
6 Fowler CJ, Carroll MB, Burns D, et al. A portable system for measuring cutaneous thresholds for warming and cooling. $J$ Neurol Neurosurg Psychiatry 1987;50:1211-5.

7 Behse F, Buchthal F. Normal sensory conduction in the nerves of the leg in man. J Neurol Neurosurg Psychiatry 1971;34:404-14.

8 Ochoa J, Mair WGP. The normal sural nerve in man. Acta Neuropathol 1969;13:197-216.

9 Jacobs JM, Love S. Qualitative and quantitative morphology of human sural nerve at different ages. Brain 1985;108:897-924.

10 Hensel H, Iggo A, Witt I. A quantitative study of sensitive cutaneous thermoreceptors with C afferent fibres. J Physiol (Lond) 1960;153:113-26.

11 Iggo A. Cutaneous thermoreceptors in primates and subprimates. J Physiol (Lond) 1969;200:403-30.

12 Bessou P, Perl ER. Response of cutaneous sensory units with unmyelinated fibres to noxious stimuli. $J$ Neurophysiol 1969; 32:1025-43.

13 Iriuchijima J, Zotterman Y. The specificity of afferent cutaneous C fibres in mammals. Acta Physiol Scand 1960;49:267-78.

14 Hensel H, Iggo A. Analysis of cutaneous warm and cold fibres in the primate. Pflugers Arch 1971;329:1-8.

15 Perl ER. Myelinated afferent fibres innervating the primate skin and their response to noxious stimuli. J Physiol (Lond) 1968;197:593-615.

16 Darian-Smith I, Johnson KO, Dykes R. Cold fibre population innervating palmar and digital skin of the monkey: responses to cooling pulses. $J$ Neurophysiol 1973;36:325-46.

17 Duclaux R, Kenshalo DR. Response characteristics of cutaneous warm receptors in the monkey. $J$ Neurophysiol 1980;43:1-15.

18 Darian-Smith I, Johnson KO, Lamotte C, et al. Warm fibers innervating palmar and digital skin of the monkey: response to thermal stimuli. J Neurophysiol 1979;42:1297-315.

19 Sumino R, Dubner R, Starkman S. Responses of small myelinated "warm" fibres to noxious heat applied to the monkey's face. Brain Res 1973;62:260-3.

20 Vallbo AB, Hagbarth K-E, Torebjork HE, et al. Somatosensory, proprioceptive, and sympathetic activity in human peripheral nerves. Physiol Rev 1979;59:919-57.

21 Torebjork HE, Hallin RG. Identification of afferent $C$ units in intact human skin nerves. Brain Research 1974;67:387-403.

22 Adriaensen $\mathrm{H}$, Gybels J, Handwerker HO, et al. Response properties of thin myelinated A-delta fibres in human skin nerves. $J$ Neurophysiol 1983;49:111-22.

23 Hallin RG, Torebjork HE, Wiesenfeld Z. Nociceptors and warm receptors innervated by $\mathrm{C}$ fibres in human skin. $J$ Neurol Neurosurg Psychiatry 1982;45:313-9.

24 Konietzny $\mathrm{F}$, Hensel $\mathrm{H}$. The dynamic response of warm units in hurnan skin nerves. Pflugers Arch 1977;370:111-4.

25 Konietzny $F$, Hensel $H$. Warm fibre activity in human skin nerves. Pflugers Arch 1975;359:265-7.

26 Jarvilehto T, Hamalaien $H$. Touch and thermal sensations: psychophysical observations and unit activity in human skin nerves. In: Kenshalo DR, ed. Sensory Functions of the Skin of Humans. New York: Plenum Press, 1980:279-95.
27 Gasser HS, Erlanger J. The role of fiber size in the establishment of a nerve block by pressure or cocaine. Am J Physiol 1929;88:581-91.

28 Gissen AJ, Covino BG, Gregus J. Differential sensitivities of mammalian nerve fibres to local anaesthetic agents. Anesthesiology 1980;53:467-74.

29 Nathan PW, Sears TA. Some factors concerned in differential nerve block by local anaesthetics. $J$ Physiol (Lond) 1961;157:565-80.

30 Franz DN, Perry RS. Mechanisms for differential block among single myelinated and non-myelinated axons by procaine. $J$ Physiol (Lond) 1974;236:193-210.

31 Ford DJ, Prithvi Raj P, Singh P, et al. Differential peripheral nerve block by local anaesthetics in the cat. Anesthesiology 1984;60:28-33.

32 Nathan PW. Observations on sensory and sympathetic function during intrathecal analgesia. $J$ Neurol Neurosurg Psychiatry 1976;39:114-21.

33 Fruhstorfer H, Zenz M, Nolte H, et al. Dissociated loss of cold and warm sensibility during regional anaesthesia. Pflugers Arch 1974;349:73-82.

34 Torebjork HE, Hallin RG. Perceptual changes accompanying controlled preferential blocking of $A$ and $C$ fibre responses in intact human skin nerves. Exp Brain Res 1973;16:321-32.

35 Mackenzie RA, Burke D, Skuse N, et al. Fibre function and perception during cutaneous nerve block. J Neurol Neurosurg Psychiatry 1975;38:865-73.

36 Fruhstorfer H, Guth H, Pfaff U. Cortical responses evoked by thermal stimuli in man. Pflugers Arch 1933;339:R 88.

37 Fruhstorfer H, Guth H, Pfaff U. Cortical responses evoked by thermal stimuli in man. In: McCallum WC, Knott JR eds. The Responsive Brain. Bristol: J. Wright \& Sons, 1976:30-3.

38 Duclaux R, Franzen O, Chatt AB, et al. Responses recorded from human scalp evoked by cutaneous thermal stimulation. Brain Res 1974:78:279-90.

39 Chatt AB, Kenshalo DR. Cerebral evoked responses to skin warming recorded from human scalp. Exp Brain Res 1977;28:449-55.

40 Jamal G, Hansen S, Weir AJ, Ballantyne JP. Thermal evoked potentials: Preliminary results. Electroencephalogr Clin Neurophysiol 1987;67:4, 74P.

41. Bazett HC, McGloane B, Brocklehurst RJ. The temperature in the tissues which accompany temperature sensations. J Physiol (Lond) 1930;69:88-112.

42 Wright GH. The latency of sensations of warmth due to radiation. J Physiol (Lond) 1951;112:344-58.

43 Lele PP, Sinclair DC. Observations on the reaction time to cutaneous thermal stimuli. J Neurol Neurosurg Psychiatry 1955; 18:120-4.

44 Fruhstorfer $\mathbf{H}$, Guth $\mathbf{H}$, Pfaff U. Thermal reaction time as a function of stimulation site. Pflugers Arch 1972;335:R49.

45 Hensel $H$. Thermoreception and temperature regulation. In: Monographs of the Physiological Society No 38. London: Academic Press, 1981. 